\title{
Risk characterization and exposure assessment in arseniasis-endemic areas of Taiwan
}

\author{
Min-Pei Ling ${ }^{\text {a }}$, Chung-Min Liao ${ }^{\text {b,* }}$ \\ ${ }^{a}$ Department of Health Risk Management, China Medical University, Taichung, 40402 Taiwan, ROC \\ ${ }^{\mathrm{b}}$ Ecotoxicological Modeling Center, Department of Bioenvironmental Systems Engineering, \\ National Taiwan University, Taipei, 10617 Taiwan, ROC
}

Received 22 August 2005; accepted 12 August 2006

Available online 2 October 2006

\begin{abstract}
This paper examines the age-specific human health risks exposed to inorganic arsenic through arsenic-contaminated farmed fish/shrimp and groundwater consumptions in arseniasis-endemic areas of blackfoot disease (BFD)-endemic area and Lanyang Plain in Taiwan, based on an probabilistic integrated risk assessment framework. We employ an age-dependent predictive physiologically-based pharmacokinetic model to account for arsenic concentrations in target organs. We reconstruct age-specific dose-response profiles for arsenicosis and arsenic-induced cancers by best fitting a pharmacodynamics-based three-parameter Hill equation model to published epidemiological data from West Bengal and Taiwan. The predicted median arsenic concentrations in age group-specific skin, lung, and bladder ranged from 2.24-5.70, 3.76-9.46, and 5.11-20.71 $\mu \mathrm{g}$ $\mathrm{g}^{-1}$ in BFD-endemic area, whereas 4.98-12.04, 8.23-19.92, and 11.07-43.45 $\mu \mathrm{g} \mathrm{g}^{-1}$ in Lanyang Plain, respectively. Risk analysis indicates that consumption of arsenic-contaminated farmed fish/shrimp and groundwater in arseniasis-endemic areas may increase threat to prevalence of arsenicosis for all age groups, whereas adults may undergo potential risks of arsenic-induced skin, lung and bladder cancers. We show that peoples in Lanyang Plain are more readily associated with higher morbidities for arsenicosis and skin cancer as well as fatalities for lung and bladder cancers than that of peoples in BFD-endemic area. Here we report the first case in which theoretical human health risks for consuming Ascontaminated farmed fish/shrimp and groundwater in the arseniasis-endemic areas are alarming under a conservative condition based on a probabilistic risk assessment framework.
\end{abstract}

(C) 2006 Elsevier Ltd. All rights reserved.

Keywords: Arsenic; Probabilistic risk assessment; Physiologically-based pharmacokinetic; Pharmacodynamic; Arseniasis-endemic; Farmed fish/shrimp

\section{Introduction}

Systemic and chronic exposure to arsenic is known to lead to serious disorders, such as vascular diseases (Blackfoot disease (BFD) and hypertension) and irritations of the skin and mucous membranes as well as dermatitis, keratosis, and melanosis (ATSDR, 2000; USEPA, 2002a,b). Inorganic arsenic is a human carcinogen, and ingestion of inorganic arsenic increases the risk of developing cancer of the bladder, liver, kidney, and skin (Abernathy et al., 2003; Yu et al., 2003). The clinical manifestations of chronic arsenic intoxication are referred to as arsenicosis (hyperpigmentation and keratosis).

\footnotetext{
* Corresponding author. Tel.: +88622363 4512; fax: +886223626433.

E-mail address: cmliao@ntu.edu.tw (C.-M. Liao).
}

Arseniasis-endemic areas are referred to the areas situated at southwestern of BFD-endemic area and northeastern of Lanyang Plain of Taiwan region (Hsueh et al., 2003; Tsai et al., 2003; Yang et al., 2003; Chen et al., 2004). The pathway of arsenic exposure to residents at BFD-endemic area is through the consumption of farmed fish mainly including tilapia (Oreochromis mossambicus), milkfish (Chanos chanos), and large-scale mullet (Liza macrolepis), whereas at Lanyang Plain, the routes of arsenic exposure include farmed smelt (Plecoglossus altivelis) and grasp shrimp (Penaeus monodon) consumption and groundwater ingestion. Farmed fish/shrimp were bioaccumulated certain amounts of arsenic from aquaculture-used As-contaminated groundwater (Lin et al., 2001; Liao et al., 2003; Lin and Chiang, 2002).

USEPA (2002a,b) addressed children's responses to environmental toxicants will be affected in which their systems absorb, distribute, metabolize and excrete chemicals. Because 
of variability in physiology and behaviors, exposures are different among population of different age groups (Ginsberg et al., 2004). In this work, we examined the variability of the exposure risk across the population to improve accuracy of assessment pertaining to the age group-specific health.

We coupled an age-dependent predictive physiologicallybased pharmacokinetic (PBPK) model to estimate arsenic concentration distributions in human blood, lung, bladder, skin, GI tract. A pharmacodynamic (PD)-based Hill equation model was employed to reconstruct age-specific dose-response functions for arsenicosis (hyperpigmentation and keratosis) and arsenic-induced cancers (skin, lung, and bladder cancers) based on published epidemiological data from West Bengal and Taiwan.

We combined the age-specific arsenic distributions in target organs and the reconstructed dose-response profiles to predict and to compare the arsenic exposure risks for children, adolescents, and adults through farmed fish/shrimp and groundwater consumption in arseiasis-endemic areas. We characterized the risk quantitatively by development of a probabilistic integrated assessment (PIA) framework that is most needed to interpret the prevalence of hyperpigmentation, keratoses, and skin cancer in which the health endpoint is morbidity, whereas fatality endpoint is for the incidence of lung and bladder cancers (NRC, 2001; Yu et al., 2003). The PIA framework are more valuable for communicating an accurate view of current scientific knowledge to those seeking information for decision-making than assessments that do not attempt to present results in a probabilistic framework.

The specific objective of this study is twofold: (1) to quantitatively estimate the inorganic arsenic distributions in human specific target organs by linking an age-dependent PBPK model and a PD-based age-specific dose-response model of noncancer/cancer effects and (2) to conduct a PIA-schemed approach based on the U.S. EPA paradigm (USEPA, 1998) to assess inorganic arsenic exposure risks to children, adolescents, and adults through consumption of popular farmed fish/shrimp and ingestion of groundwater in BFD-endemic area and Lanyang Plain.

\section{Materials and methods}

\subsection{Arsenic levels in farmed fish from BFD-endemic area}

Liao et al. (2003) and Lin et al. (2001) have conducted a field bioaccumulation investigation in tilapia farms in BFD-endemic area and reported that the mean arsenic pond water concentrations ranged from $26.3 \pm 16$ (mean $\pm \mathrm{sd}$ ) to $251.7 \pm 12.2 \mu \mathrm{g} \mathrm{L}^{-1}$, whereas the mean arsenic concentration in tilapia tissues were $29.3,10.9,5.37,5.04$, and $3.55 \mu \mathrm{g} \mathrm{g}^{-1}$ dry wt in intestine, stomach, liver, gill, and muscle, respectively. Huang et al. (2003) reported that inorganic arsenic level is measured to be $7.4 \%$ of total arsenic in farmed tilapia from BFD-endemic area. Lin et al. (2004) have collected samples of farmed milkfish and ambient water from aquacultural ponds in BFD-endemic area and reported that the average arsenic concentration in the pond water was $27 \pm 1 \mu \mathrm{g} \mathrm{L}^{-1}$ (mean $\pm \mathrm{sd}$ ), whereas average arsenic level in milkfish tissue was $15.2 \pm 5.1 \mu \mathrm{g} \mathrm{g}^{-1}$ dry wt. Donohue and Abernathy (1999) reported that the amount of inorganic arsenic in general seafood ranged from $<3-7 \%$ of the total arsenic. Due to the available information is scarce, we practically assumed a mean value of $5 \%$ to account for inorganic arsenic content of total arsenic in milkfish. Lin et al. (2001) have sampled farmed large-scale mullet and ambient water from aquacultral ponds in Putai and Yichu located in BFDendemic area and indicated that the mean concentrations of arsenic in the culture ponds ranged from 13.0 to $169.7 \mu \mathrm{g} \mathrm{L}^{-1}$, whereas the mean concentration of arsenic in large-scale mullet was $2.40 \pm 2.06 \mu \mathrm{g} \mathrm{g}^{-1}$ dry wt. Maher et al. (1999) reported that inorganic arsenic level is account for $3.4 \%$ of the total arsenic in mullet.

\subsection{Arsenic levels in farmed fish/shrimp and groundwater at Lanyang Plain}

Recently, several articles have been devoted to the study of human health effects from arsenic exposure in Lanyang Plain (Hsueh et al., 2003; Tsai et al., 2003; Yang et al., 2003; Chen et al., 2004). Because of the abundance of underground water in the area, residents in Lanyang Plain have been using groundwater from shallow wells $(<40 \mathrm{~m}$ in depth) since the late 1940 in that arsenic levels in groundwater ranged from undetectable $\left(<0.15 \mu \mathrm{g} \mathrm{L}^{-1}\right)$ to $3590 \mathrm{\mu g} \mathrm{L}^{-1}$ (Chiou et al., 2001). Although the implementation of a tap-water system was begun in Lanyang Plain in the 1990s, some residents around $50 \%$ still drank the arsenic-contaminated groundwater or used for aquaculture (Lin and Chiang, 2002).

Lin and Chiang (2002) have conducted a field investigation to analyze the arsenic levels in groundwater located at Tungsha and Wuchieh in Lanyang Plain, indicating that there were $64.4 \%$ of 180 groundwater samples were higher than the Taiwan drinking water standard $\left(10 \mu \mathrm{g} \mathrm{L}^{-1}\right)$, whereas the maximum concentration of arsenic was $1145 \mu \mathrm{g} \mathrm{L}^{-1}$. Lin and Chiang (2002) have also collected samples of smelt and grass shrimp from seven culture ponds in Lanyang Plain and reported that the levels of arsenic in smelt and grass shrimp were 25.6 and $16.65 \mu^{-1} \mathrm{~g} \mathrm{~g}^{-1}$ dry wt, respectively. Due to the available information is scarce, we assumed that inorganic arsenic is also $5 \%$ of the total arsenic in smelt. For shrimp, on the other hand, Larsen et al. (1997) reported that inorganic arsenic was estimated to be $1.6 \%$ of the total arsenic in shrimp.

Chiou et al. (2001) noted that the variation in arsenic level in groundwater at Lanyang Plain was much more striking than the arsenic level in groundwater at BFD-endemic area. They further pointed out that the main exposure to inorganic

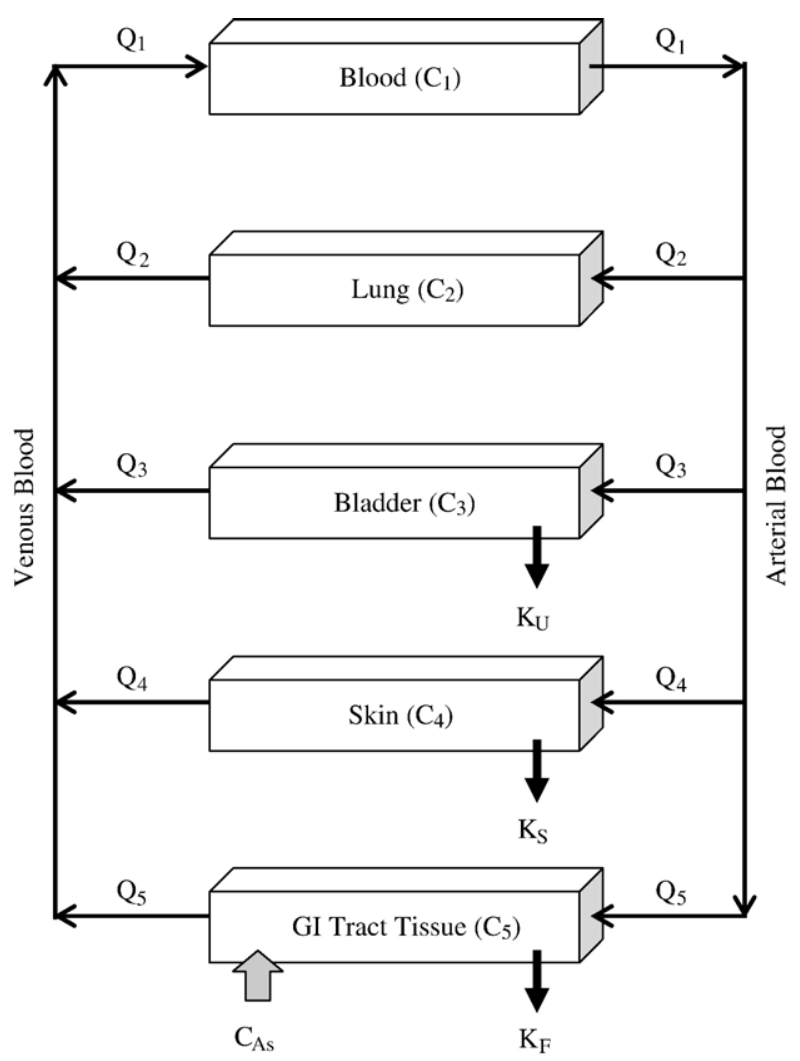

Fig. 1. Schematic diagram of physiologically based pharmacokinetic (PBPK) model for As in human organs in that a PBPK model structure consists of lung, bladder, skin, and GI tract that interconnected by blood circulation. 
arsenic of local residents in Lanyang Plain was through groundwater ingestion. We used the reported data from ROCEPA (2004) to estimate the arsenic levels in groundwater from significant arsenic-contaminated areas of Tungsha, Wuchieh, and Chuangwei in Lanyang Plain. Our analysis shows that the mean arsenic level in groundwater ranged from undetectable $\left(<0.5 \mu \mathrm{g} \mathrm{L}^{-1}\right)$ to $373 \mu \mathrm{g} \mathrm{L}^{-1}$. Huang et al. (2003) reported that the inorganic arsenic level was measured to be $87.34 \%$ of the total arsenic in groundwater.

\subsection{Age-dependent PBPK model}

An age-dependent PBPK model was used to estimate inorganic arsenic distributions in specific human target organs through arsenic-contaminated farmed fish/shrimp and groundwater consumptions for different age groups. The PBPK model structure features lung (compartment 2), bladder (compartment 3), skin (compartment 4), and GI tract (compartment 5), which are interconnected by blood (compartment 1) circulation (Fig. 1). The essence of almost all PBPK models can be described by a linear dynamic equation (Yu, 1999a,b; Lien et al., 2001; Leggett et al., 2003; Gentry et al., 2004),

$\frac{\mathrm{d}\left\{C_{H, i}(t)\right\}}{\mathrm{d} t}=[K]\left\{C_{H, i}(t)\right\}+[X]\{u(t)\}$,

where $\left\{C_{H, i}(t)\right\}$ is a state variable vector which describes the chemical concentration in each assigned human target organ $i,\{u(t)\}$ represents an input vector of chemical concentration in farmed fish/shrimp or groundwater, $[K]$ is a state matrix which describes the diffusion exchange rate between target organs based on Fig. 1,

$[K]=\left[\begin{array}{c}-\left(Q_{2}+Q_{3}+Q_{4}+Q_{5}\right) \frac{F_{D}}{V_{1}} \\ \frac{Q_{2} F_{D}}{W_{2}} \\ \frac{Q_{3} F_{D}}{W_{3}} \\ \frac{Q_{4} F_{D}}{W_{4}} \\ \frac{Q_{5} F_{D}}{W_{5}}\end{array}\right.$

$\frac{Q_{2}}{R_{2} V_{1}}$
$-\left(\frac{Q_{2}}{R_{2} W_{2}}\right)$
0
0
0

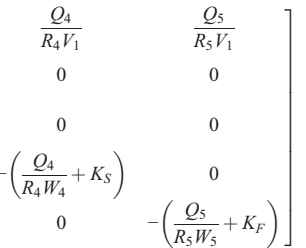

and $[X]$ is a constant input matrix describes the exchange rate into the target organ,

$[X]=\left[\begin{array}{lllll}0 & 0 & 0 & 0 & \frac{\mathrm{IR} \alpha}{W_{5}}\end{array}\right]^{T}$.

A steady-state condition is assumed in Eq. (1). Solving for the equilibrium arsenic concentrations in human lung $\left(C_{2}\right)$, bladder $\left(C_{3}\right)$, and skin $\left(C_{4}\right)$,

$C_{2}=\frac{Q_{2} F_{D} \mathrm{IJCG}}{\left[\mathrm{AFHIJ}-\left(\mathrm{HIJB} Q_{2} F_{D}+\mathrm{FIJC} Q_{3} F_{D}+\mathrm{FHJD} Q_{4} F_{D}+\mathrm{FHIE} Q_{5} F_{D}\right)\right]}$,

$C_{3}=\frac{Q_{3} F_{D} \mathrm{FICG}}{\left[\mathrm{AFHIJ}-\left(\mathrm{HIJB} Q_{2} F_{D}+\operatorname{FIJC} Q_{3} F_{D}+\mathrm{FHJD} Q_{4} F_{D}+\operatorname{FHIE} Q_{5} F_{D}\right)\right]}$,

$C_{4}=\frac{Q_{4} F_{D} \mathrm{FJCG}}{\left[\mathrm{AFHIJ}-\left(\mathrm{HIJB} Q_{2} F_{D}+\mathrm{FIJC} Q_{3} F_{D}+\mathrm{FHJD} Q_{4} F_{D}+\operatorname{FHIE} Q_{5} F_{D}\right)\right]}$,

where

$A=F_{D}\left(Q_{2}+Q_{3}+Q_{4}+Q_{5}\right), B=Q_{2} R_{2}^{-1}, C=Q_{3} R_{3}^{-1}$,

$D=Q_{4} R_{4}^{-1}, E=Q_{5} R_{5}^{-1}, F=\operatorname{IR} \alpha C_{\mathrm{As}}, G=Q_{5} R_{5}^{-1}+\mathrm{IR} K_{\mathrm{F}} T$,

$H=Q_{4} R_{4}^{-1}+K_{\mathrm{S}} \mathrm{BW}_{i}$, and $I=Q_{3} R_{3}^{-1}+K_{\mathrm{U}} W_{3, i}$,

in that $C_{\mathrm{As}}$ is the arsenic concentration in farmed fish/shrimp ( $\mu \mathrm{g} \mathrm{g}^{-1}$ wet wt) or groundwater $\left(\mu \mathrm{g} \mathrm{L}^{-1}\right) ; Q_{i}$ is the diffusive exchange rate of organ $i\left(\mathrm{~L} \mathrm{~d}^{-1}\right) ; F_{\mathrm{D}}$ is the binding coefficient of arsenic concentration to plasma proteins $\left(\mathrm{g} \mathrm{L}^{-1}\right) ; R_{\mathrm{i}}$ defines as $C_{i} / C_{\mathrm{di}}$, which denotes the partition coefficient or is referred to as an organ/blood equilibrium distribution ratio for linear binding in specific organ $i$ $\left(\mathrm{L} \mathrm{g}^{-1}\right)$ in that $C_{i}$ is the total arsenic concentration in human target organ $i(\mu \mathrm{g}$ $\left.\mathrm{g}^{-1}\right)$ and $C_{\mathrm{di}}$ is the dissolved arsenic concentration in the blood leaving target organ $i\left(\mu \mathrm{g} \mathrm{mL}^{-1}\right)$; IR is the daily farmed fish/shrimp ingestion rate $\left(\mathrm{g} \mathrm{d}^{-1}\right)$ or groundwater daily ingestion rate $\left(\mathrm{L} \mathrm{d}^{-1}\right) ; \mathrm{BW}_{i}$ is the whole body weight for population of different age group (g); $W_{i}$ is the weight of human target organ $i$ $(\mathrm{g}) ; W_{3, i}$ is the organ weight of bladder for age-specific population $(\mathrm{g}) ; \alpha$ is absorption efficiency of arsenic (\%); $T$ is time to $95 \%$ steady state in GI tract (d); $K_{\mathrm{U}}$ is the urine elimination rate $\left(\mathrm{g} \mathrm{g}^{-1} \mathrm{~d}^{-1}\right) ; K_{\mathrm{S}}$ is the sweat elimination rate ( $\mathrm{g}$ $\left.\mathrm{g}^{-1} \mathrm{~d}^{-1}\right)$; and $K_{\mathrm{F}}$ is the fecal elimination rate $\left(\mathrm{g} \mathrm{g}^{-1} \mathrm{~d}^{-1}\right)$. The input variables needed to simulate the arsenic level in major organs for human include human physiological parameters $\left(Q_{i}, F_{\mathrm{D}}, R_{i}, \mathrm{IR}, \mathrm{BW}_{i}, W_{3, i}, \alpha, T\right)$, biokinetic parameters $\left(K_{\mathrm{U}}, K_{\mathrm{S}}, K_{\mathrm{F}}\right)$, and chemical parameter $\left(C_{\mathrm{As}}\right)$.

\subsection{Age-specific dose-response profiles and risk models}

We reconstructed age-specific dose-response models for morbidity and fatality effects versus arsenic level in human target organs by best fitting a PD-based threeparameter Hill equation model (Melnick et al., 1998) to the previously published dose-response functions expressed as the quadratic-exponential forms for arsenicosis and arsenic-induced cancers based on epidemiological data from West Bengal and Taiwan (Tables 1 and 2) (Yu et al., 2003). The Hill equation model was used because it allows comparison of cooperativily among different dose-response profiles that can validate the observations of published studies and can explicitly show the responses are dependent on the noncancer/cancer

Table 1

Published dose-response functions of the quadratic-exponential form for arsenicosis and As-induced cancers based on epidemiological data from West Bengal and Taiwan

\section{Dose-Response Functions $^{\mathrm{a}}$}

\section{Arsenicosis}

Keratosis,

hyperpigmentation

$$
p(C)=1-\exp \left(-\left(q_{1} C+q_{2} \mathrm{C}^{2}\right)\right)
$$

Arsenic-induced cancers

Skin cancer

$$
p(C)=\int_{0}^{\infty} p(C, t) \lambda \exp (-\lambda t) \mathrm{d} t
$$

where $p(C, t)=\begin{gathered}1-\exp \left(-\left(q_{1} C+q_{2} C^{2}\right)\right. \\ \left.(t-m)^{k} H(t-m)\right)\end{gathered}$

Internal (lung and liver) cancer

$$
h(C)=\int_{0}^{\infty} h(C, t) \lambda \exp (-\lambda t) \mathrm{d} t
$$

$$
\text { where } \begin{aligned}
h(C, t)= & k\left(q_{1} C+q_{2} C^{2}\right) \\
& (t-m)^{k-1} H(t-m)
\end{aligned}
$$

Gender-adjusted distribution function ${ }^{\mathrm{c}}$

$$
p(C)=0.509 p_{m}(C)+0.491 p_{f}(C)
$$

${ }^{\mathrm{a}} p(C)$ and $h(C)$ are the prevalence ratio and incidence rate as a function of As concentration $C\left(\mu \mathrm{g} \mathrm{g}^{-1}\right) ; p(C, t)$ and $h(C, t)$ are the prevalence ratio and incidence rate as a function of As concentration $C\left(\mu \mathrm{g} \mathrm{g}^{-1}\right)$ and age $t(\mathrm{yr})$. Parameter values $\left(q_{1}, q_{2}, k\right.$, and $\left.m\right)$ were taken from Yu et al. (2003) (see Table 2); and $\lambda$ is an age distribution parameter: $\lambda=t^{-1}$ where $t$ is the average age (yr). In this study, the population of Taiwanese are estimated to be $73.35 \mathrm{yrs}$ for males and 79.05 yrs for females (DOS, 2004).

${ }^{\mathrm{b}} H(t-m)=0$ for $t<m, H(t-m)=1$ for $t \geq m, H$ denotes the Heaviside function.

${ }^{c} p_{m}(C)$ and $p_{f}(C)$ is the dose-response functions for males and females. The values of 0.509 and 0.491 appeared in Eq. (T-6) are estimated based on the population of Taiwanese that comprised of $50.9 \%$ males and $49.1 \%$ females, respectively (DOS, 2004). 
Table 2

Parameters used to calculate the dose-response models in Table 1 for Hyperpigmentation, Keratosis, and As-induced cancers ${ }^{\mathrm{a}}$

\begin{tabular}{|c|c|c|c|c|}
\hline Arsenicosis & \multicolumn{2}{|l|}{$q_{1}$} & \multicolumn{2}{|c|}{$q_{2}$} \\
\hline \multicolumn{5}{|l|}{ Keratosis } \\
\hline Male & \multicolumn{2}{|c|}{$1.223 \times 10^{-4}$} & \multicolumn{2}{|c|}{0} \\
\hline Female & \multicolumn{2}{|c|}{$6.416 \times 10^{-5}$} & \multicolumn{2}{|c|}{$2.717 \times 10^{-9}$} \\
\hline \multicolumn{5}{|l|}{ Hyperpigmentation } \\
\hline Male & \multicolumn{2}{|c|}{$2.678 \times 10^{-4}$} & \multicolumn{2}{|c|}{0} \\
\hline Female & \multicolumn{2}{|c|}{$1.217 \times 10^{-4}$} & \multicolumn{2}{|c|}{0} \\
\hline As-induced cancer & $q_{1}$ & $q_{2}$ & $k$ & $m$ \\
\hline \multicolumn{5}{|l|}{ Skin cancer } \\
\hline Male & $7.936 \times 10^{-10}$ & $1.640 \times 10^{-12}$ & 2.950 & 6.873 \\
\hline Female & $6.291 \times 10^{-11}$ & $3.265 \times 10^{-13}$ & 3.231 & 9.000 \\
\hline \multicolumn{5}{|l|}{ Lung cancer } \\
\hline Male & $1.4672 \times 10^{-11}$ & 0 & 3.9195 & 21.4946 \\
\hline Female & 0 & $6.1194 \times 10^{-14}$ & 3.5137 & 17.0978 \\
\hline \multicolumn{5}{|l|}{ Bladder cancer } \\
\hline Male & 0 & $7.3394 \times 10^{-17}$ & 5.1306 & 14.7025 \\
\hline Female & 0 & $2.2225 \times 10^{-13}$ & 3.4732 & 33.0365 \\
\hline
\end{tabular}

${ }^{\mathrm{a}}$ The listed parameters are based on the parameters from $p(C), h(C), p(C, t)$, $h(C, t)$ in Table 1 that are adopted from Yu et al. (2003).

endpoints and arsenic concentration. The reconstructed dose-response profiles for prevalence $\left(P_{i}\right)$ and incidence $\left(I_{i}\right)$ have the forms as,

$P_{i}=\frac{P_{\max } \times C_{H, i}^{n}}{\mathrm{EC}_{50, i}^{n}+C_{H, i}^{n}}$,

$F_{i}=\frac{F_{\max } \times C_{H, i}^{n}}{\mathrm{EC}_{50, i}^{n}+C_{H, i}^{n}}$,

where $P_{i}$ and $I_{i}$ are prevalence (\%) and incidence (\%), respectively; $P_{\max }$ and $I_{\max }$ are human maximum prevalence and incidence of those exposed to arsenic through farmed fish/shrimp and groundwater consumption; $C_{H, i}$ is the internal arsenic concentration in human target organ $i\left(\mu \mathrm{g} \mathrm{g}^{-1}\right)$; $\mathrm{EC}_{50, \mathrm{i}}$ is the $50 \%$ effect concentration $\left(\mu \mathrm{g} \mathrm{g}^{-1}\right)$ of the $P_{\max }$ and $I_{\max }$ for target organ $i$; and $n$ is the Hill coefficient which is a measure of cooperativity. An $n=1$ represents a linear response at low concentration, an $n>1$ represents a sublinear (sigmoidal) response indicating positive cooperatively, and $n<1$ represents a supralinear response (Melnick et al., 1998).

The cumulative distribution function (CDF) of predicted prevalence and incidence functions for a given organ-specific arsenic concentration in human, $F$ $\left(P_{i} \mid C_{H, i}\right)$ and $F\left(I_{i} \mid C_{H, i}\right)$, could be expressed symbolically as conditional CDF,

$F\left(P_{i} \mid C_{H, i}\right)=\Phi\left(\frac{100 \times C_{H, i}^{n}}{\mathrm{EC}_{50, i}^{n}+C_{H, i}^{n}}\right)$,

$F\left(I_{i} \mid C_{H, i}\right)=\Phi\left(\frac{100 \times C_{H, i}^{n}}{\mathrm{EC}_{50, i}^{n}+C_{H, i}^{n}}\right)$,

where $\Phi(\bullet)$ is the cumulative standard normal distribution.

Risk at a specific arsenic concentration in a specific human target organ can be expressed as a joint probability function or exceedence profile, which describes the probability of exceeding the concentration associated with a particular degree of carcinogenic or noncarcinogenic effect,

$R\left(P_{i}\right)=F\left(C_{H, i}\right) F\left(P_{i} \mid C_{H, i}\right)$,

$R\left(I_{i}\right)=F\left(C_{H, i}\right) F\left(I_{i} \mid C_{H, i}\right)$,

where $R\left(P_{i}\right)$ and $R\left(I_{i}\right)$ are the prevalence and incidence risk for a specific organ $i$ at concentration $C_{H, i}$, and $F\left(C_{H, i}\right)$ is the $\mathrm{CDF}$ of having organ concentration $C_{H, i}$.

\subsection{Uncertainty and sensitivity analyses}

In exposure and risk assessment, there are several sources of uncertainty. Due to inherent natural variability, model variables can be defined in terms of a probability density function that was derived from a limited set of observations. The data, however, may not be representative of the entire population, and sample statistics may not be accurate estimates of the true values of the population parameters. This leads to uncertainty in the parameter estimation procedures. To explicitly account for this uncertainty/variablity and its impact on the estimation of expected risk, a Monte Carlo (MC) simulation was adopted. To test the convergence and the stability of the numerical output, we performed independent runs at $1,4,5$, and 10 thousand iterations with each parameter sampled independently from the appropriate distribution at the start of each replicate. Largely because of limitations in the data used to derive model parameters, inputs were assumed to be independent. The result showed that 10,000 iterations were sufficient to ensure the stability of results.

A sensitivity analysis was conducted to identify the critical input variables that presented in the uncertainty and variability analysis of the PIA framework for human health assessment. The sensitivity of each variable relative to one another was assessed by calculating rank correlation coefficients between each input and output during simulations and then estimated each input contribution to the output variance by squaring the output variance and normalizing to $100 \%$. The MC simulation and sensitivity analysis were implemented using Crystal Ball $^{\circledR}$ (Version 2000.2, Decisionerring, Inc., Denver, CO, USA). We

Table 3

Input physiological parameters for children, adolescents, and adults to define distributions for Monte Carlo (MC) simulation

\begin{tabular}{|c|c|c|c|}
\hline Parameters & $\begin{array}{l}\text { Children } \\
(4-12 \mathrm{yrs})^{\mathrm{a}}\end{array}$ & $\begin{array}{l}\text { Adolescents } \\
(13-18 \text { yrs })^{\mathrm{a}}\end{array}$ & $\begin{array}{l}\text { Adults } \\
(19-65 \mathrm{yrs})^{\mathrm{a}}\end{array}$ \\
\hline $\begin{array}{l}\text { Body weight, } \\
\mathrm{BW}_{i}(\mathrm{~kg})^{\mathrm{b}}\end{array}$ & $\mathrm{TN}(29.12,7.39)$ & $\mathrm{TN}(54.21,5.37)$ & $\mathrm{TN}(60.05,4.26)$ \\
\hline $\begin{array}{l}\text { Bladder weight, } \\
W_{3, i}(\mathrm{~g})^{\mathrm{c}}\end{array}$ & $\mathrm{TN}(177.70,45.74)$ & $\mathrm{TN}(270.64,53.93)$ & $\mathrm{TN}(289.93,55.63)$ \\
\hline \multicolumn{4}{|l|}{ Ingestion rate, $\mathrm{IR}^{\mathrm{d}}$} \\
\hline \multicolumn{4}{|l|}{$\begin{array}{l}\text { Farmed seafood } \\
\left(\mathrm{g} \mathrm{d}^{-1}\right)\end{array}$} \\
\hline Tilapia & $\mathrm{LN}(16.57,1.36)$ & $\mathrm{LN}(25.96,1.24)$ & $\mathrm{LN}(27.82,1.25)$ \\
\hline Milkfish & $\mathrm{LN}(18.07,1.37)$ & $\mathrm{LN}(28.31,1.25)$ & $\mathrm{LN}(30.34,1.25)$ \\
\hline $\begin{array}{l}\text { Large-scale } \\
\text { mullet }\end{array}$ & $\mathrm{LN}(0.92,1.37)$ & $\mathrm{LN}(1.44,1.24)$ & $\mathrm{LN}(1.54,1.25)$ \\
\hline Smelt & $\mathrm{LN}(1.50,1.36)$ & $\operatorname{LN}(2.34,1.25)$ & $\mathrm{LN}(2.51,1.25)$ \\
\hline Grass shrimp & $\mathrm{LN}(0.20,1.36)$ & $\mathrm{LN}(0.32,1.24)$ & $\mathrm{LN}(0.34,1.25)$ \\
\hline $\begin{array}{l}\text { Groundwater } \\
\left(\mathrm{L} \mathrm{d}^{-1}\right)\end{array}$ & $\mathrm{LN}(1.27,1.37)$ & $\mathrm{LN}(2.00,1.24)$ & $\mathrm{LN}(2.14,1.25)$ \\
\hline
\end{tabular}

${ }^{a}$ Exposure duration (median) — children: 8 yrs, adolescents: 16 yrs, adults: 42 yrs.

${ }^{\mathrm{b}}$ Information adopted from $\mathrm{DOH}(2002)$ in that $\mathrm{TN}(\mathrm{m}, \mathrm{sd})$ is a truncated normal distribution with mean (m) and standard deviation (sd).

${ }^{c}$ Adopted and estimated from Mann et al. (1996).

${ }^{d}$ Values were calculated from Fisheries Administration, Council of Agriculture (FACOA, 2004) and Department of Statistics (DOS, 2004). LN $(\mathrm{gm}, \mathrm{gsd})$ is a lognormal distribution with geometric mean $(\mathrm{gm})$ and geometric standard deviation (gsd) 
Table 4

Input chemical and biokinetic parameters to define distributions for Monte Carlo (MC) simulation

\begin{tabular}{ll}
\hline Parameters & Value \\
\hline Chemical parameter & \\
Arsenic concentration in farmed seafood, & \\
$C_{\mathrm{As}-\mathrm{S}, i}\left(\mu \mathrm{g} \mathrm{g}^{-1}\right.$ wet wt) & \\
Tilapia $^{\mathrm{a}}$ & \\
Milkfish $^{\mathrm{b}}$ & $\mathrm{LN}(1.98,1.56)$ \\
Large-scale mullet $^{\mathrm{c}}$ & $\mathrm{LN}(3.60,1.39)$ \\
Smelt $^{\mathrm{d}}$ & $\mathrm{LN}(0.57,1.09)$ \\
Grass shrimp $^{\mathrm{d}}$ & $\mathrm{LN}(6.37,1.10)$ \\
Arsenic concentration in groundwater, & $\mathrm{LN}(1.14,1.10)$ \\
$C_{\mathrm{As}-\mathrm{W}}\left(\mu \mathrm{g} \mathrm{L}^{-1}\right)^{\mathrm{e}}$ & $\mathrm{LN}(42,1.99)$
\end{tabular}

Biokinetic parameters ${ }^{\mathrm{f}}$

Urine elimination rate, $K_{\mathrm{U}}\left(\mathrm{d}^{-1}\right)$

$\mathrm{LN}(1.79,1.10)$

Fecal elimination rate, $K_{\mathrm{F}}\left(\mathrm{d}^{-1}\right)$

$\mathrm{LN}(0.029,1.11)$

${ }^{a}$ Value was taken from Liao et al. (2003).

b Value was taken from Lin et al. (2004).

c Value was taken from Lin et al. (2001).

${ }^{d}$ Value was taken from Lin and Chiang (2002).

e Value was taken from ROCEPA (2004).

${ }^{\mathrm{f}}$ Values were taken from Yu (1999b).

incorporated probability distributions into MC simulation to obtained 2.597.5th percentiles as $95 \% \mathrm{CI}$ for all uncertainty analyses.

\subsection{Model parameterization}

\subsubsection{Physiological parameters: $B W_{i}, W_{3, i}, I R$}

Distributions of the average body weight $\left(\mathrm{BW}_{i}\right)$ of Taiwanese children, adolescents, and adults were fitted to the data obtained from Department of Health (DOH), Taiwan (2002). Here, adults were defined as individuals from ages 19 to $65 \mathrm{yrs}$, adolescents were defined as individuals from ages 13 to $18 \mathrm{yrs}$, whereas children were defined as individuals from ages 4 to 12 yrs. To account this uncertainty, we constructed truncated normal (TN) distributions based on the $\pm 10 \%$ for the input variables and had the optimal $\chi^{2}$ and KolmogorovSmirnov (K-S) goodness-of-fit. We estimated average farmed fish/shrimp ingestion rate (IR) by dividing the annual consumption quantities and the trade of fishery import products of tilapia, milkfish, and large-scale mullet in BFD-endemic areas, and smelt and grass shrimp in Lanyang Plain by the numbers of local residents (age $>5 \mathrm{yrs}$ ) (FACOA, 2004; DOS, 2004). The daily ingestion rate of groundwater (IR) was estimated $2 \mathrm{~L} \mathrm{~d}^{-1}$ per person in Lanyang Plain. We approximated these data using a lognormal (LN) distribution. The $W_{3, I}$ and IR values were adjusted to the standard BW of $\mathrm{TN}(55.69 \mathrm{~kg}, 11.45)$ (ages range from 4-65 yrs) for children, adolescents, and adults (Meacher et al., 2002). For instance, $W_{3, i}$ can be calculated as $W_{3, i}=W_{3} \times\left(\mathrm{BW}_{i} / \mathrm{TN}(55.69,11.45)\right)^{2 / 3}($ Table 3$)$.

\subsubsection{Chemical and biokinetic parameters: $C_{A s-S, i}, C A s_{-} W, K U$ and $K F$}

Distributions of arsenic in tissues of tilapia, milkfish, and large-scale mullet, smelt, and grass shrimp were fitted to the polled field observations from arseniasis-endemic areas which measured by Liao et al. (2003), Lin et al. (2001, 2004), and Lin and Chiang (2002), and the selected LN distributions had the optimal $\mathrm{K}-\mathrm{S}$ and $\chi^{2}$ goodness-of-fit. Distribution of groundwater arsenic concentration in Lanyang Plain was best fitted to the published data obtained from ROCEPA (2004), and the selected LN distribution also had the optimal K-S and $\chi^{2}$ goodness-of-fit. The estimated bladder and GI tract elimination rates were adopted from Yu (1999b). We assigned the parameters based on $\pm 10 \%$ of base case values and the selected $\mathrm{LN}$ distributions had the acceptable $\chi^{2}$ and $\mathrm{K}-\mathrm{S}$ fits in that optimizations using either statistics yielded gm and gsd. Leggett et al. (2003) indicated that the elimination percentages for human in bladder, GI tract and skin were $0.85,0.13$, and 0.02 , respectively, showing that the sweat elimination rate is much less than the elimination rates in bladder and GI tract. Hence, we ignored the sweat elimination rate (Table 4).

\subsubsection{Dose-response parameters: $E C_{50}$ and $C S F_{\text {corr }}$}

We estimated the probability distributions of age-specific $\mathrm{EC}_{50}$ values for arsenicosis and arsenic-induced cancers based on the published dose-response functions from $\mathrm{Yu}$ et al. (2003). The corrected cancer slope factors $\left(\mathrm{CSF}_{\text {corr }}[(\mathrm{mg}\right.$ $\left.\left.\mathrm{kg}^{-1} \mathrm{~d}^{-1}\right)^{-1}\right]$ ) for the dose-response functions of lung and bladder cancers were estimated based on the benchmark dose followed U.S. EPA approach (USEPA, 2000a,b) (Table 5).

\section{Results and discussion}

\subsection{Multiple-pathway arsenic exposure assessment}

Fig. 2 depicts the exposure profile of the box plots of interquartile and $50 \%$-tile predictions associated with whisker plots indicating $10 \%$ and $90 \%$-tile predictions of arsenic contents in children, adolescents, and adults target organs from BFD-endemic area and Lanyang Plain. The estimated physiologically-based parameters of blood perfusion rate, partition coefficient, fraction arsenic dissolved in blood, time to 95\% steady state in GI tract, and absorption efficiency among target organs in PBPK model were reported only as average values (Table 6). Results demonstrate that the distribution of arsenic concentration in human bladder is more highly skewed with a long tail at higher

Table 5

Input dose-response parameters for children, adolescents, and adults to define distributions for Monte Carlo (MC) simulation

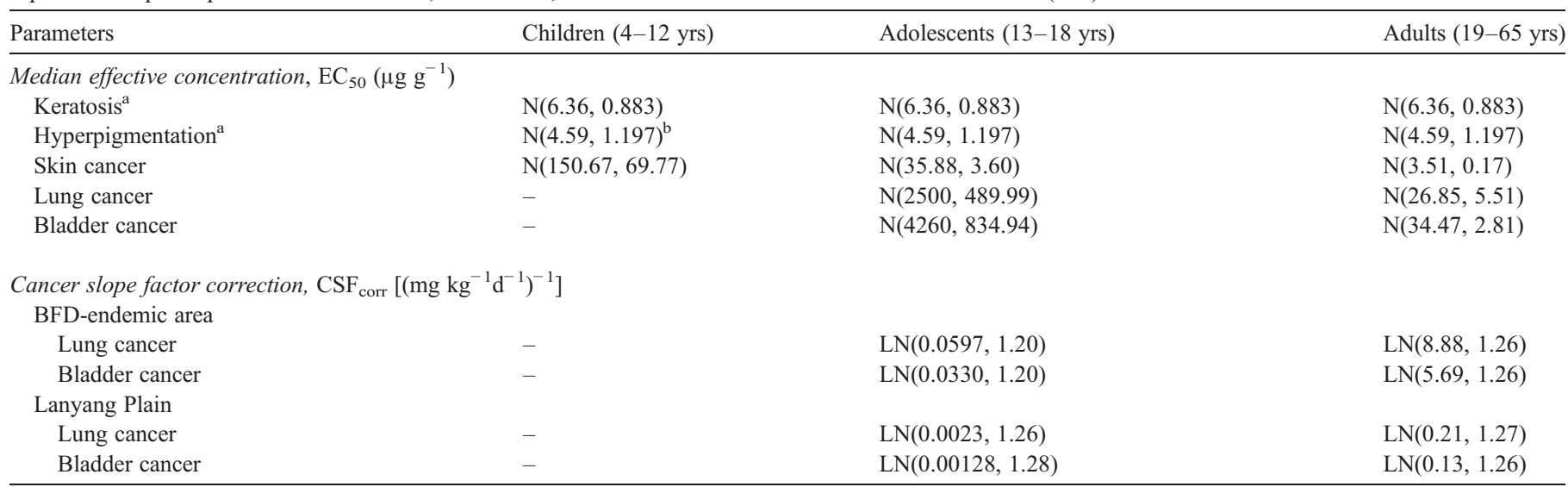

\footnotetext{
${ }^{\mathrm{a}}$ The $\mathrm{EC}_{50}$ values for hyperpigmentation and keratosis are age-independent.
}

${ }^{\mathrm{b}} \mathrm{N}(\mathrm{m}, \mathrm{sd})$ is a normal distribution with mean $(\mathrm{m})$ and standard deviation (sd) 


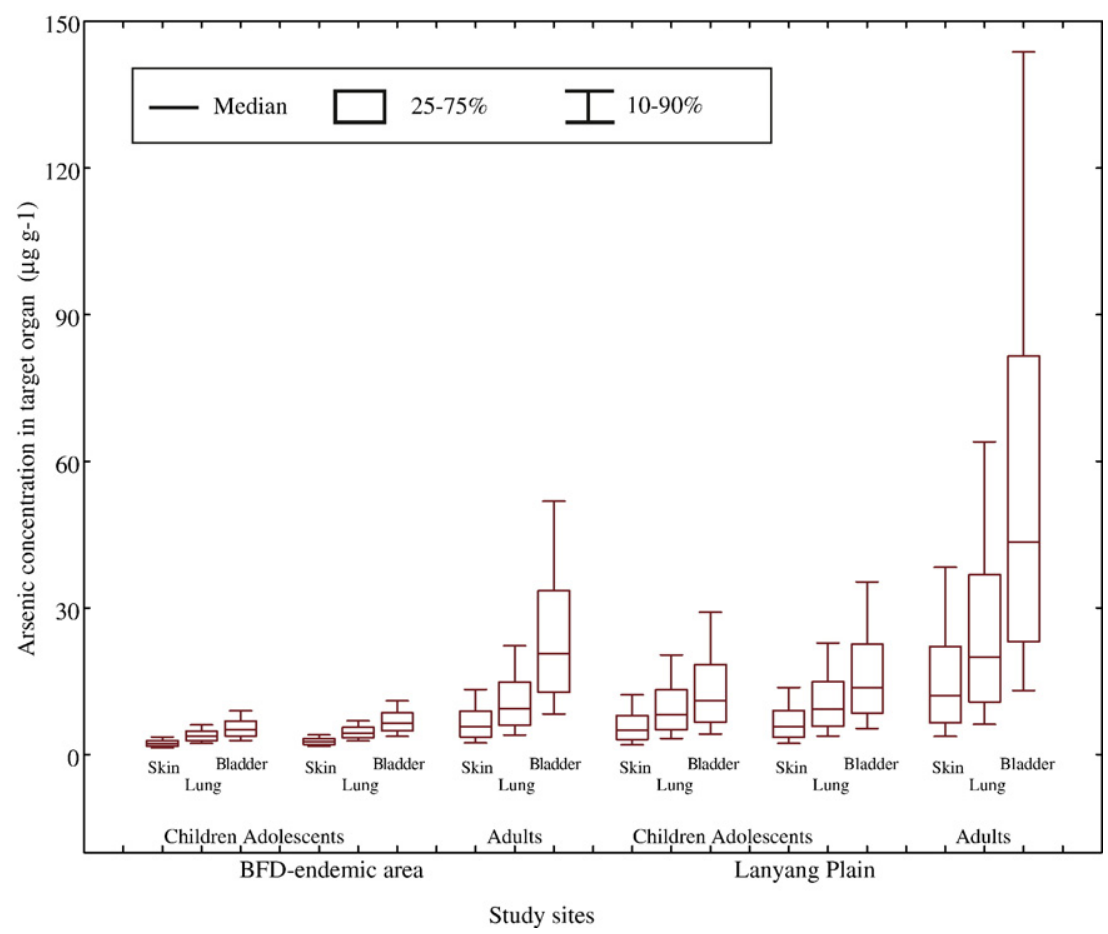

Fig. 2. Box and whisker plot representations of distributions of As concentration in human skin, lung, and bladder with children, adolescents, and adults in BFDendemic area and Lanyang Plain.

concentration, and estimated human bladder arsenic concentration has a higher uncertainty as quantified by the variance in BFD-endemic area and Lanyang Plain (Fig. 2). The arsenic levels in adult target organs are higher than those in children and adolescents. Fig. 2 also indicates that the arsenic contents of local residents living in Lanyang Plain are higher than those in BFD-endemic area. Since residence in Lanyang Plain drinks groundwater and residence from BFD-endemic area do not drink underground water. The inorganic arsenic level accounts for $87.34 \%$ of total arsenic in groundwater in Lanyang Plain, that are much higher than the seafood inorganic arsenic level (1.6-7\%). This may explain in part why the As concentration in target organs at BFD-

Table 6

Physiologically based parameter for human used for PBPK model simulation

\begin{tabular}{llc}
\hline Parameters & Symbol & Mean value \\
\hline Blood perfusion rate $\left(\mathrm{L} \mathrm{d}^{-1}\right)^{\mathrm{a}}$ & & \\
Lung & $Q_{2}$ & 230.4 \\
Bladder & $Q_{3}$ & 1368 \\
Skin & $Q_{4}$ & 504.0 \\
GI tract & $Q_{5}$ & 1382.4 \\
& & \\
Partition coefficient $\left(\mathrm{L} \mathrm{g}^{-1}\right)^{\mathrm{b}}$ & $R_{2}$ & \\
Lung:blood & $R_{3}$ & 4.15 \\
Bladder:blood & $R_{4}$ & 4.15 \\
Skin:blood & $R_{5}$ & 2.5 \\
GI tract:blood & $F_{\mathrm{D}}$ & 2.5 \\
Fraction As dissolved in blood $\left.(\mathrm{g} \mathrm{L})^{-1}\right)^{\mathrm{c}}$ & $T$ & 0.2 \\
Time to 95\% steady state in GI tract (d) & 1 \\
Absorption efficiency of As $(\%)^{\mathrm{e}}$ & $\alpha$ & 85 \\
\hline
\end{tabular}

${ }^{a}$ Values were taken from Mann et al. (1996) and Leggett et al. (2003).

b Values were taken from Yu (1999b).

${ }^{c}$ Adopted from Leggett et al. (2003).

${ }^{\mathrm{d}}$ Estimated from Lawrence and Gobas (1997).

e Adopted from Caussy (2003). endemic area contaminated by As is lower than that of in Lanyang Plain.

The median arsenic concentrations among three age groups indicate that bladder has the highest range values of 5.11-20.71 and 11.07$43.45 \mu \mathrm{g} \mathrm{g}^{-1}$ than those of in skin of 2.24-5.70 and 4.98-12.04 $\mu \mathrm{g} \mathrm{g}^{-1}$ and lung of 3.76-9.46 and 8.23-19.92 $\mu \mathrm{g} \mathrm{g}^{-1}$ in BFD-endemic area and Lanyang Plain, respectively. Lin et al. (2005) reported that tissue accumulations of inorganic arsenic in rabbit bladder after chronic dosing for 30 days had the highest value than that of in lung and skin. Hughes et al. (2003) also pointed out that the arsenic level in mice bladder had higher accumulation capacity after 9 and 17 repeated daily arsenate exposure.

\subsection{Age-specific concentration-response relationships assessment}

Here we combined the exposure distribution profiles and the reconstructed dose-response profiles to predict and to compare the human arsenic exposure risks for local residents in BFD-endemic area and Lanyang Plain, respectively. We fitted optimally the PD-based Hill equation model to published dose-response functions (Table 1, Fig. 3J-R) to obtain the reconstructed age-specific dose-response profiles (Fig. 4A-I) for arsenicosis and arsenic-induced cancers. The Hill equation model and a 10,000 MC simulation provided an adequate fit for the data $\left(\chi^{2}\right.$ goodness-of-fit, $P>0.5$ ).

The $n$ and $\mathrm{EC}_{50}$ values clearly show that there were apparent differences in sensitivity to arsenic in children, adolescents, and adults health effects except arsenicosis. Yu et al. (2003) reported that the prevalence ratios of hyperpigmentation and keratosis do not change with age under constant concentrations, resulting in the $n$ and $\mathrm{EC}_{50}$ values of hyperpigmentation and keratosis do not vary with age neither (Table 1 and Eq. (T-1)). Regression lines (Fig. 3A-I) from the nonlinear Hill threeparameter model transformations of published dose-response model (Table 1, Fig. 3J-R) had good fit as judged by $r^{2}$ values $(0.857-0.998$, $P<0.05)$. The Hill coefficients $(n)$ for arsenicosis $(1.344-1.402)$ from all 

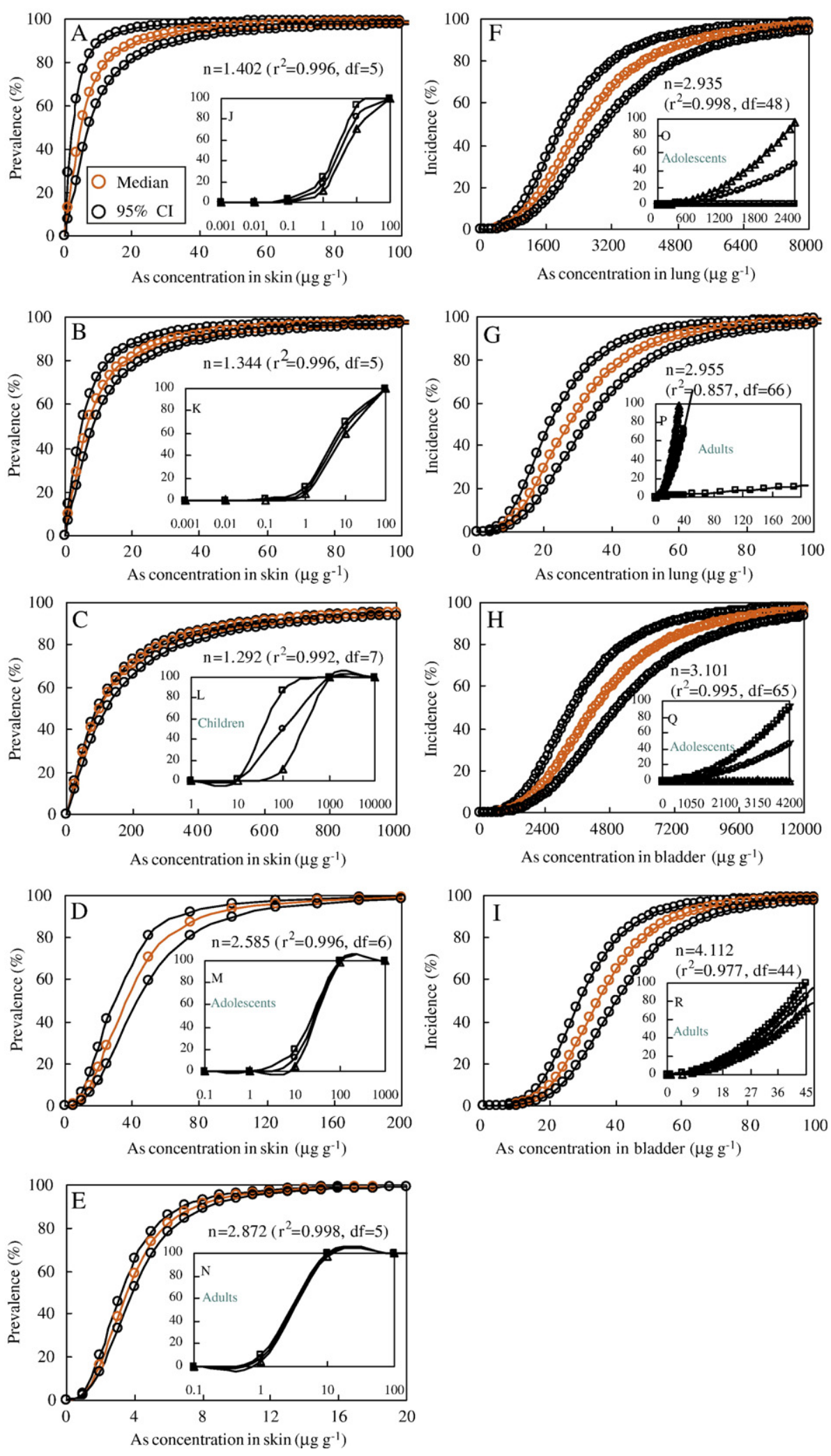

Fig. 3. Reconstructed dose-response profiles with $95 \%$ confidence interval (CI) for relationships between human health effects and As concentration based on Hill equation model regarding arsenicosis of (A) hyperpigmentation, (B) keratosis, and As-induced cancers of (C)-(E) skin cancer for children, adolescents, and adults, (F), (G) lung and (H), (I) bladder cancers for adolescents and adults, as well as (J)-(R) the published dose-response models adopted from Yu et al. (2003) with 95\% CI for arsenicosis and As-induced cancers. 
A
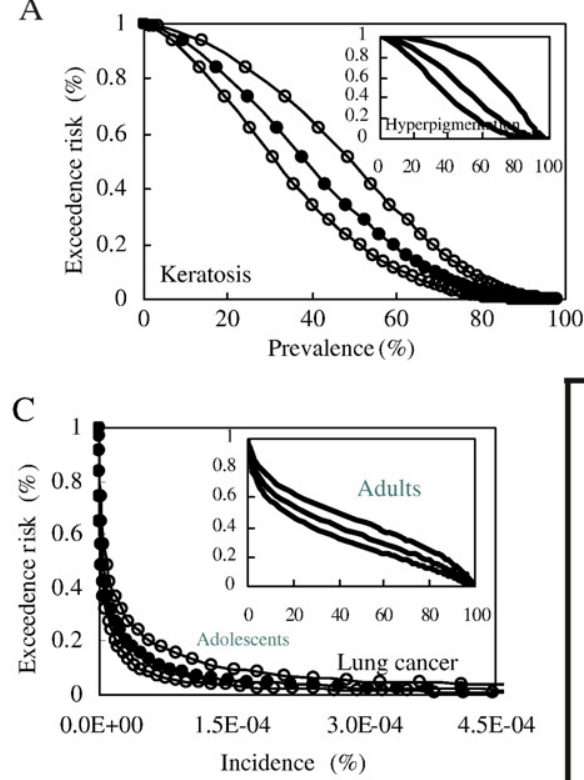

$\mathrm{D}$

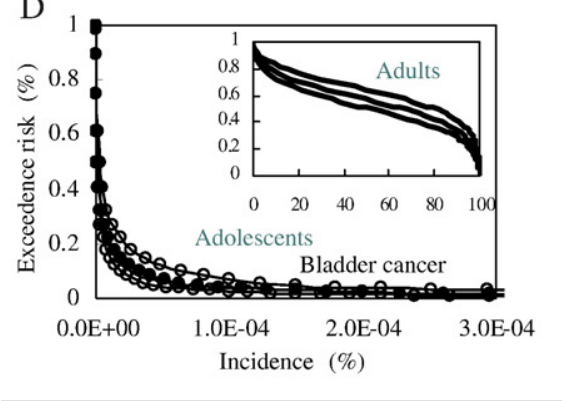

B

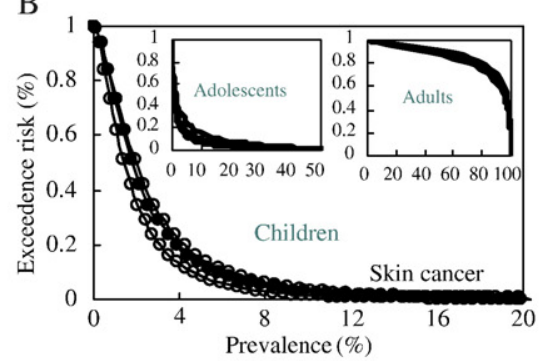

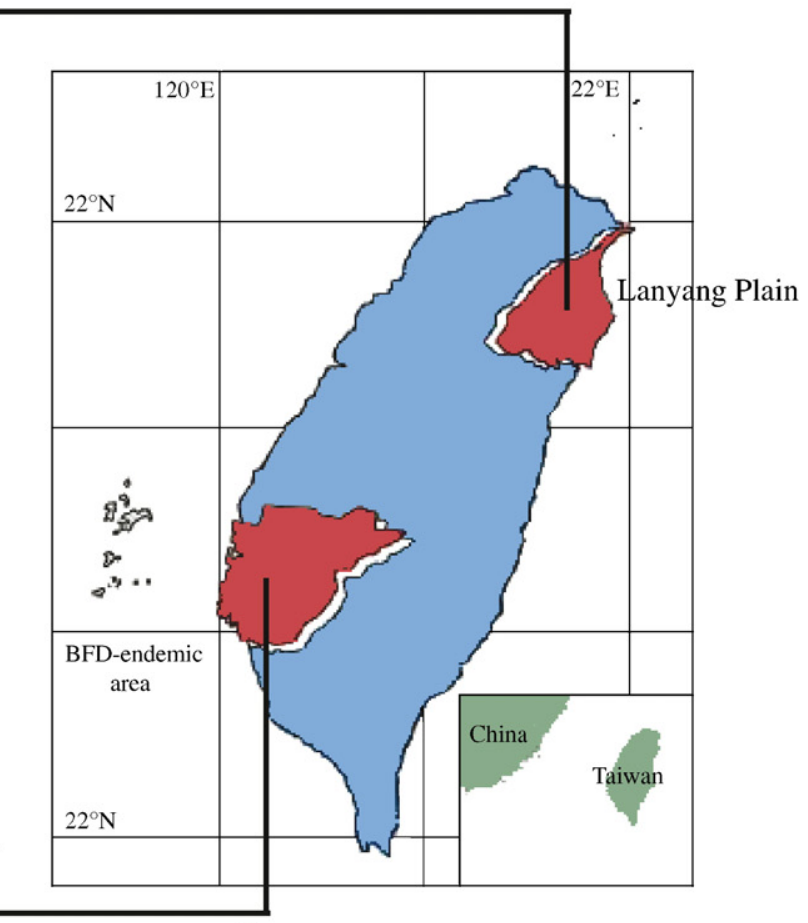
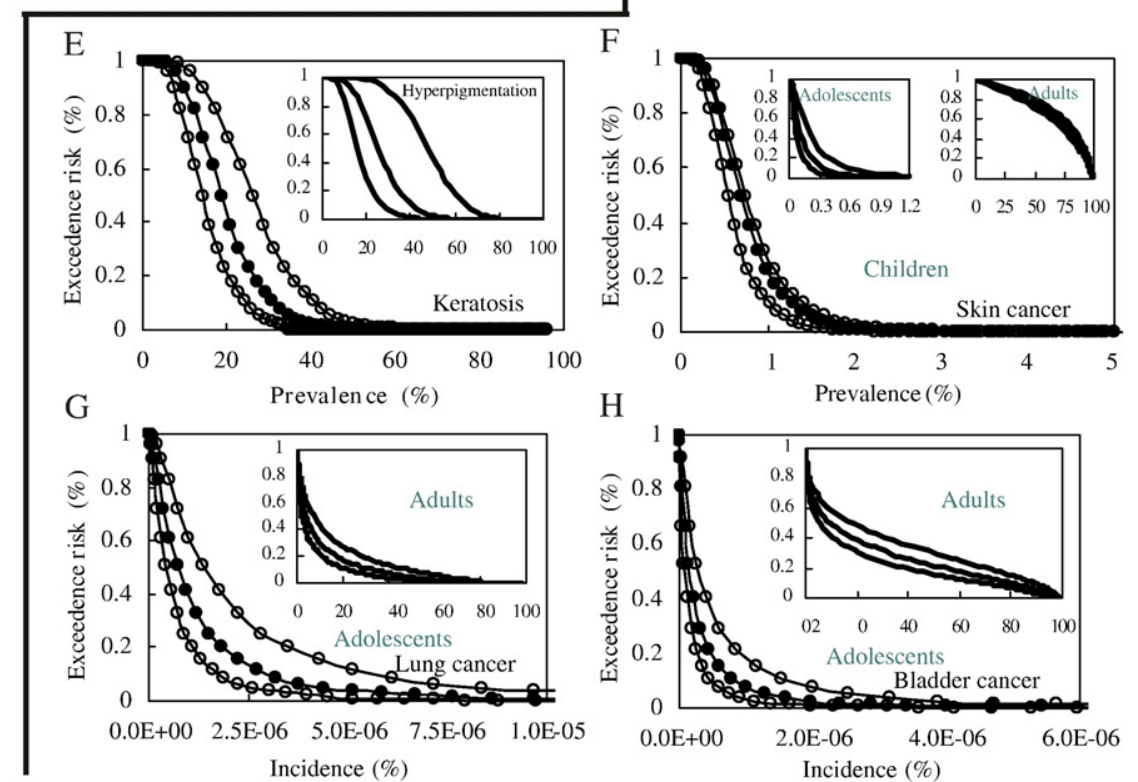

$\mathrm{H}$

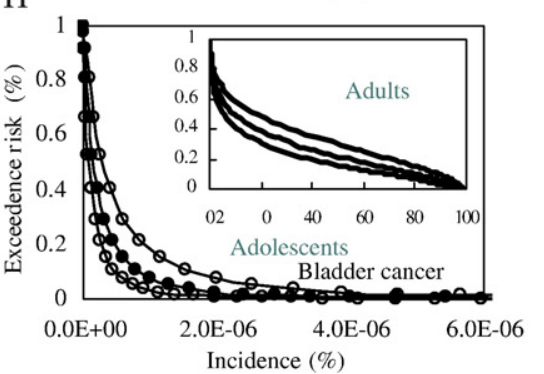

Fig. 4. Exceedence risk functions with $95 \%$ confidence interval (CI) in noncarcinogenic effects: (A) hyperpigmentation, keratosis and carcinogenic effects: (B) skin cancer for children, adolescents, and adults, (C) lung cancer and (D) bladder cancer for adolescents and adults according to local fish-specific ingestion rates of BFD-endemic area, as well as (E)- $(\mathrm{H})$ according to local fish-specific and groundwater ingestion rates of Lanyang Plain in Taiwan.

population and for arsenic-induced cancers (1.292-4.112) from agespecific population are indicative of positive cooperatively $(n>1)$. Fig. $3 \mathrm{~A}$ and $\mathrm{B}$ show the calculated $\mathrm{EC}_{50}$ values are $4.59 \mu \mathrm{g} \mathrm{g}^{-1}(95 \% \mathrm{CI}$ :
2.25-6.94) for hyperpigmentation and $6.36 \mu \mathrm{g} \mathrm{g}^{-1}$ (95\% CI: 4.63-8.09) for keratosis. For skin cancer, the median $\mathrm{EC}_{50}$ values are 100,36 , and $3.2 \mu \mathrm{g} \mathrm{g}^{-1}$ for children, adolescents, and adults, respectively. On the other 
hand, the median $\mathrm{EC}_{50}$ values for lung and bladder cancers are 2500 and $4300 \mu \mathrm{g} \mathrm{g}^{-1}$ for adolescents, whereas 28 and $34 \mu \mathrm{g} \mathrm{g}^{-1}$ for adults, respectively.

\subsection{Morbidity and fatality risks}

A probabilistic representation of risk curves shown in Fig. 4 were based on the exposure and effect profiles for people consumptions of farmed fish/shrimp and groundwater in BFD-endemic area and Lanyang Plain, respectively. Because of variability and uncertainty in model parameters from Eqs. (8) and (9) describing the exceedence CDFs associated with a particular degree of prevalence and incidence (Fig. 4), we applied the plotted probabilities calculated from the outcome of the $\mathrm{MC}$ simulation to estimate risks. In BFD-endemic area, the probabilities that $90 \%$ or more of local residents affected by keratosis (per 100,000) (risk $=0.90)$ are approximately 9970 (95\% CI: 7420-14,510), whereas $13,720(95 \%$ CI: $8,180-30,230)$ by hyperpigmentation, i.e., the probability is 0.90 that at least 9970 (per 100,000) and 13,720 (per 100,000 ) of people will be affected by keratosis and hyperpigmentation, respectively (Table 7). Table 7 shows the exceedence risks (per 100,000) (risk $=0.90$ ) of fatality effect for lung cancer in arseniasis-endemic area ranged from $1.76 \times 10^{-4}-2.68 \times 10^{-4}$ for adolescents and $303-853$ for adults, whereas for bladder cancer ranged from $1.94 \times 10^{-5}-4.50 \times 10^{-5}$ for adolescents and 204-524 for adults.

The present risk analysis suggests that consumption of arseniccontaminated farmed fish/shrimp and groundwater in arseniasisendemic areas may increase threat to prevalence of arsenicosis for all age groups, whereas adults may undergo potential risks of arsenicinduced skin, lung and bladder cancers. (Fig. 4 and Table 7). Due to the difference in exposure duration of adults: $61 \mathrm{yrs}(4-18 \mathrm{yrs})$ and adolescents: 12 yrs (4-65 yrs), the exceedence risk for adults is much higher than that of adolescents (Table 7). Most notably, we show that peoples in Lanyang Plain are more readily associated with higher morbidities for arsenicosis and skin cancer as well as fatalities for lung and bladder cancers than that of peoples in BFD-endemic area.

\subsection{Sensitivity analysis}

Sensitivity analysis indicates that the most important variables for human arsenic exposure are arsenic concentrations in farmed tilapia for

Table 7

Exceedence risk (per 100,000) (risk $=0.90)$ with $95 \%$ confidence interval $(\mathrm{CI})$ in human health effects

\begin{tabular}{lll}
\hline & BFD-Endemic Area & Lanyang Plain \\
\hline Keratosis & $9970(7420-14,510)$ & $13,524(10,201-19,231)$ \\
Hyperpigementation & $13,720(8180-30,230)$ & $18,492(11,374-37,628)$
\end{tabular}

Skin cancer

Children

Adolescents

37 (23-66)

Adults

$342(272-374)$

37 (23-65)

$481(382-526)$

$24,290(19,860-29,870) \quad 51,800(45,370-58,810)$

Lung cancer

Adolescents

Adults

$1.76 \times 10^{-4}\left(1.04 \times 10^{-7}\right.$
$\left.-3.33 \times 10^{-4}\right)$
$303(179-577)$

$2.68 \times 10^{-4}$

$\left(1.58 \times 10^{-4}-5.08 \times 10^{-4}\right)$ 853 (504-1612)

Bladder cancer Adolescents

$\begin{array}{ll}1.94 \times 10^{-5} & 4.50 \times 10^{-5}\left(2.59 \times 10^{-5}\right. \\ \left(1.12 \times 10^{-5}-3.84 \times 10^{-5}\right) & \left.-8.85 \times 10^{-5}\right) \\ 204\left(110^{-418)}\right. & 524(286-1067)\end{array}$

Table 8

Probabilistic sensitivity analyses for PBPK and dose-response models

\begin{tabular}{|c|c|c|c|}
\hline \multicolumn{2}{|l|}{ Input parameters } & \multirow[t]{2}{*}{ Correlation } & \multirow[t]{2}{*}{$\begin{array}{l}\text { Contribution to } \\
\text { variance }(\%)^{\mathrm{a}}\end{array}$} \\
\hline \multicolumn{2}{|l|}{ PBPK model } & & \\
\hline \multirow[t]{5}{*}{ BFD-endemic area } & As concentration in tilapia & 0.73 & 59.1 \\
\hline & $\begin{array}{l}\text { As concentration } \\
\text { in milkfish }\end{array}$ & 0.39 & 16.7 \\
\hline & Fecal elimination rate & -0.3 & 9.7 \\
\hline & Weight of human bladder & -0.25 & 6.7 \\
\hline & Urine elimination rate & -0.25 & 6.7 \\
\hline \multirow[t]{5}{*}{ Lanyang Plain } & As level in groundwater & 0.97 & 94.6 \\
\hline & Fecal elimination rate & -0.13 & 1.7 \\
\hline & Weight of human bladder & -0.13 & 1.6 \\
\hline & Urine elimination rate & -0.11 & 1.2 \\
\hline & As level in grass shrimp & 0.03 & 0.1 \\
\hline \multicolumn{4}{|c|}{ Dose-response model } \\
\hline \multicolumn{2}{|c|}{$\begin{array}{l}\text { As concentration in } \\
\text { human organ } i\end{array}$} & 0.996 & 99.4 \\
\hline \multicolumn{2}{|l|}{$\begin{array}{l}\text { Median effective } \\
\text { concentration }\end{array}$} & -0.070 & 0.6 \\
\hline
\end{tabular}

${ }^{a}$ Contribution to variance calculated as sum of squared rank correlation coefficients normalized to $100 \%$.

BFD-endemic area and groundwater arsenic level for Lanyang Plain, which contribute to approximately 59 and $95 \%$ of output variances, respectively (Table 8). For dose-response model, on the other hand, arsenic concentration in human organ is the key parameter, that contribution to variance is $99 \%$ (Table 8 ). It is plausible that sensitivity analysis might offer guidance for risk management and ranks different implementing options as follows. Reducing farmed tilapia consumption rate in BFD-endemic area and stopping groundwater ingestion in Lanyang Plain are the most effective control measure options for decreasing carcinogenic risk potential from arsenic-induced cancers.

\subsection{Implications}

If farmed fish is not contaminated by arsenic, it is the healthy food with valuable nutrients, such as omega-3 polyunsaturated fatty acid and muscle proteins, that are well known to have certain benefits to human health effects (Huang et al., 2004; Tokur et al., 2004). Our present study, however, indicates that consumption of arsenic-contaminated farmed fish/ shrimp may pose potential arsenicosis and skin cancer risks. To precisely determine the risk/benefit ratios from consumption of farmed fish are complicated, cautious interpretation of present data may substantially reduce the likelihood in dealing with uncertainty and risk management.

Here we report the first case in which theoretical human health risks for consuming As-contaminated farmed fish/shrimp and groundwater in the arseniasis-endemic areas are alarming under a conservative condition based on a probabilistic risk assessment framework. We believe that the PIA framework - probabilistic PBPK/PD model together with risk diagrams - is an effective representation of state-of-the-art results of scientific assessments for human arsenic exposure through consumption of contaminated farmed fish/shrimp and groundwater. Despite the great uncertainty in many aspects of integrated assessment, the arsenic toxicity, arsenic concentration in farmed species or groundwater, and daily ingestion rates that may modify the outcomes of risk estimate, cautious interpretation of observations obtained from current epidemiological data can substantially reduce this likelihood.

Although the suitability and effectiveness of techniques for presenting uncertain results is context-dependent, we suggest that our probabilistic framework and methods can be taken seriously because 
they produce general conclusions that are more robust than estimates made with a limited set of scenarios or without probabilistic presentations of outcomes. Besides, our predictive risk modeling technique also offers a risk-management framework for future discussion in deriving risk thresholds human arsenic exposure.

\section{References}

Abernathy CO, Thomas DJ, Calderon RL. Health effects and risk assessment of arsenic. J Nutr 2003;133:1536S-8S.

ATSDR (Agency for Toxic Substances and Disease Registry). Toxicological profile for arsenic. Washington, DC: Agency for Toxic Substances and Disease Registry, U.S. Department of Health and Human Services, Public Health Service; 2000.

Caussy D. Case studies of the impact of understanding bioavailability: arsenic. Ecotoxicol Environ Saf 2003;56:164-73.

Chen CL, Hsu LI, Chiou HY, Hsueh YM, Chen SY, Wu MM, et al. Ingested arsenic, cigarette smoking, and lung cancer risk - a follow-up study in arseniasisendemic areas in Taiwan. JAMA J Am Med Assoc 2004;292:2984-90.

Chiou HY, Chiou ST, Hsu YH, Chou YL, Tseng CH, Wei ML, et al. Incidence of transitional cell carcinoma and arsenic in drinking water: a follow-up study of 8102 residents in an arseniasis-endemic area in northeastern Taiwan. Am J Epidemiol 2001;153:411-8.

DOH (Department of Health). Health and national health insurance annual statistics information service. Taipei, Taiwan: Department of Health, Ministry of Interior, Executive Yuan, ROC; 2002 [in Chinese].

Donohue JM, Abernathy CO. Exposure to inorganic arsenic from fish and shellfish. In: Chappell WR, Abernathy CO, editors. Arsenic Exposure and Health Effects. Amsterdam: Elsevier; 1999. p. 89-98.

DOS (Department of Statistics). Yearly statistics of population. Taipei, Taiwan: Department of Statistics, Ministry of Interior, Executive Yuan, ROC; 2004 [in Chinese].

FACOA (Fisheries Administration, Council of Agriculture). Fisheries statistical yearbook. Taipei, Taiwan: Fisheries Administration, Council of Agriculture, Executive Yuan, ROC; 2004.

Gentry PR, Covington TR, Mann S, Shipp AM, Yager JW, Clewell HJ. Physiologically based pharmacokinetic modeling of arsenic in the mouse. J Toxicol Environ Health, Part A 2004;67:43-71.

Ginsberg G, Hattis D, Sonawane B. Incorporating pharmacokinetic differences between children and adults in assessing children's risks to environmental toxicants. Toxicol Appl Pharmacol 2004;198:164-83.

Hsueh YM, Ko YF, Huang YK, Chen HW, Chiou HY, Huang YL, et al. Determinants of inorganic arsenic methylation capability among residents of the Lanyang Basin, Taiwan: arsenic and selenium exposure and alcohol consumption. Toxicol Lett 2003;137:49-63.

Huang YK, Lin KH, Chen HW, Chang CC, Liu CW, Yang MH, et al. Arsenic species contents at aquaculture farm and in farmed mouthbreeder (Oreochromis mossambicus) in blackfoot disease hyperendemic areas. Food Chem Toxicol 2003;41:1491-500.

Huang SL, Weng YM, Huang CH. Lipid peroxidation in sarcoplasmic reticulum and muscle of tilapia is inhibited by dietary vitamin E supplementation. J Food Biochem 2004;28:101-11.

Hughes MF, Kenyon EM, Edwards BC, Mitchell CT, Del Razo LM, Thomas DJ. Accumulation and metabolism of arsenic in mice after repeated oral administration of arsenate. Toxicol Appl Pharmacol 2003;191:202-10.

Larsen EH, Quetel CR, Munoz R, FialaMedioni A, Donard OFX. Arsenic speciation in shrimp and mussel from the Mid-Atlantic hydrothermal vents. Mar Chem 1997;57:341-6.

Lawrence GS, Gobas FAPC. A pharmacokinetic analysis of interspecies extrapolation in dioxin risk assessment. Chemosphere 1997;35:427-52.

Leggett RW, Williams LR, Melo DR, Lipsztein JL. A physiologically based biokinetic model for cesium in the human body. Sci Total Environ 2003;317: $235-55$.
Liao CM, Chen BC, Singh S, Lin MC, Liu CW, Han BC. Arsenic bioaccumulation and toxicity in tilapia (Oreochromis mossambicus) from blackfoot disease area in Taiwan. Environ Toxicol 2003;18:252-9.

Lien GJ, McKim JM, Hoffman AD, Jenson CT. A physiologically based toxicokinetic model for lake trout (Salvelinus namaycush). Aquat Toxicol 2001;51:335-50.

Lin JK, Chiang HC. Arsenic concentration in drinking well water in Lanyang area and its preliminary health risk assessment. Taipei, Taiwan: National Science Council, ROC; 2002. NSC-90-2218-E-238-003.

Lin MC, Liao CM, Liu CW, Singh S. Bioaccumulation of arsenic in aquacultural large-scale mullet Liza macrolepis from blackfoot disease area in Taiwan. Bull Environ Contam Toxicol 2001;67:91-7.

Lin MC, Cheng HH, Lin HY, Chen YC, Chen YP, Chang-Chien GP, et al. Arsenic accumulation and acute toxicity in aquacultural juvenile milkfish (Chanos chanos) from blackfoot disease area in Taiwan. Bull Environ Contam Toxicol 2004;72:248-54.

Lin CJ, Wu MH, Hsueh YM, Sun SSM, Cheng AL. Tissue distribution of arsenic species in rabbits after single and multiple parenteral administration of arsenic trioxide: tissue accumulation and the reversibility after washout are tissue-selective. Cancer Chemother Pharmacol 2005;55:170-8.

Maher W, Goessler W, Kirby J, Raber G. Arsenic concentrations and speciation in the tissues and blood of sea mullet (Mugil cephalus) from Lake Macquarie NSW, Australia. Mar Chem 1999;68:169-82.

Mann S, Droz PO, Vahter M. A physiologically based pharmacokinetic model for arsenic exposure. II. Validation and application in humans. Toxicol Appl Pharmacol 1996;140:471-86.

Meacher DM, Menzel DB, Dillencourt MD, Bic LF, Schoof RA, Yost LJ, et al. Estimation of multimedia inorganic arsenic intake in the US population. Human Ecol Risk Assess 2002;8:1697-721.

Melnick RL, Kohn MC, Dunnick JK, Leininger JR. Regenerative hyperplasia is not required for liver tumor induction in female $\mathrm{B} 6 \mathrm{C} 3 \mathrm{~F}(1)$ mice exposed to trihalomethanes. Toxicol Appl Pharmacol 1998;148:137-47.

NRC (National Research Council). Arsenic in drinking water. Washington, DC: National Academy Press; 2001.

ROCEPA (Republic of China Environmental Protection Agency). Groundwater monitoring data. soil and groundwater remediation web. http://wq.epa.gov. tw/WQ/Public2/ImageGW.asp2004.

Tokur B, Polat A, Beklevik G, Ozkutuk S. Changes in the quality of fishburger produced from Tilapia (Oreochromis niloticus) during frozen storage (-18 degrees C). Eur Food Res Technol 2004;218:420-3.

Tsai SY, Chou HY, The HW, Chen CM, Chen CJ. The effects of chronic arsenic exposure from drinking water on the neurobehavioral development in adolescence. Neurotoxicology 2003;24:747-53.

USEPA (United States Environmental Protection Agency). Guidelines for ecological risk assessment. Washington, DC: United States Environmental Protection Agency; 1998. EPA-630-R-95-002F.

USEPA (United States Environmental Protection Agency). List of drinking water contaminants and MCLs. Washington, DC: United States Environmental Protection Agency; 2002a. EPA-816-F-02-013.

USEPA (United States Environmental Protection Agency). Child-specific exposure factors handbook (Interim report). Washington, DC: United States Environmental Protection Agency; 2002b. EPA-600-P-00-002B.

Yang CY, Chang CC, Tsai SS, Chuang HY, Ho CK, Wu TN. Arsenic in drinking water and adverse pregnancy outcome in an arseniasis-endemic area in northeastern Taiwan. Environ Res 2003;91:29-34.

Yu D. A physiologically based pharmacokinetic model of inorganic arsenic. Regul Toxicol Pharmacol 1999a;29:128-41.

Yu D. A physiologically modeling of inorganic arsenic: a short-term oral exposure model for humans. Chemosphere 1999b;39:2737-47.

Yu WH, Harvey CM, Harvey CF. Arsenic in groundwater in Bangladesh: a geostatistical and epidemiological framework for evaluating health effects and potential remedies. Water Resour Res 2003;39:1146, doi:10.1029/ 2002WR001327. 